\title{
Educação Superior no Brasil: panorama da contemporaneidade
}

\author{
Brazilian higher education: contemporary panorama
}

\author{
Rosa Virgínia Diniz ${ }^{1}$ \\ ${ }^{1}$ Centro Universitário Max Planck | Coordenação de Inovação Educacional \\ Indaiatuba | SP | Brasil. Contato: rosaecologica@ hotmail.com \\ http://orcid.org/0000-0001-6902-3727
}

Pedro L. Goergen ${ }^{2}$

${ }^{2}$ Universidade de Sorocaba| Pós-Graduação em Educação

Sorocaba | SP | Brasil. Contato: pedro.goergen@hotmail.com

http://orcid.org/http://orcid.org/0000-0001-9539-9752

\begin{abstract}
Resumo: O objetivo do presente artigo é apresentar uma síntese da realidade do ensino superior brasileiro na atualidade a partir de seus aspectos legais, históricos e contextuais com o fito de instrumentalizar pesquisas cujo foco seja este nível educacional. A pesquisa bibliográfica realizou-se a partir de consulta à legislação atinente ao setor, bem como, aos autores que debatem a temática de forma a condensar dados que possibilitaram delinear o quadro da contemporaneidade. Restou observada a formulação de uma estrutura notadamente privatizada, historicamente consolidada, e fortalecida pelas novas demandas e estratégias governamentais para oportunizar tal etapa do ensino, convergentes com um modelo econômico neoliberal.
\end{abstract}

Palavras-chave: Ensino superior. Modelo educacional. Expansão neoliberal.

Abstract: The aim of this article is to show a synthesis of the Brazilian higher education reality in the present time, based on its legal, historical and contextual aspects, in order to instrumentalize researches that focus on this educational level. The bibliographical research was carried out based on a referring to the legislation related to the subject, as well as the authors who debate the theme in order to condense data that allowed to delineate the contemporary configuration. It was verified the formulation of a notably privatized structure, historically consolidated, and strengthened by the new demands and governmental strategies to give opportunity to this stage of teaching, converged with a neoliberal economic model.

Key words: Higher education. Educacion model. Neoliberal expansion.

DOI: http://dx.doi.org/10.1590/S1414-40772019000300002

Este é um artigo publicado em acesso aberto sob uma licença Creative Commons https://creativecommons.org/licenses/by-nc/4.0/ 


\section{Introdução}

Este artigo apresenta uma investigação em que sintetiza dados e contextos da educação superior brasileira, tomando em conta que na contemporaneidade tal modalidade de ensino é mencionada pelo Informe Delors (2001) como um dos motores do desenvolvimento econômico, cultural e científico acumulado pela humanidade. Tal concepção converge com os relatórios do Banco Mundial que a associam a redução da pobreza e base para o desenvolvimento econômico, especialmente necessárias na América Latina (BORGES, 2010).

Ainda que não seja intenção debater de modo profundo a respeito da história e características da educação superior brasileira, dadas as limitações próprias de um artigo, esse estudo traz considerações sobre o tema com o intuito de apresentar tal realidade e servir de base de análise para diversos outras pesquisas desenvolvidas cuja temática corresponda ao ensino superior do Brasil contemporâneo.

Feitas tais considerações, divide-se este trabalho em três partes distintas, desenvolvidas a partir de ampla consulta de referencial teórico. A primeira traz as características do ensino superior do Brasil desde sua previsão normativa, enquanto a segunda expõe aspectos mais históricos e contextuais com vistas a orientar a compreensão da lógica de sua configuração. Por fim, o terceiro item coloca em discussão a ideia de qualidade da educação e problematiza as múltiplas matrizes e critérios que podem orientar tal perspectiva.

Em sede de considerações finais restou observada a clara tendência neoliberal do modelo de educação superior adotado no Brasil, e o esvaziamento da concepção de qualidade de ensino que passa a ser balizada apenas pelas avaliações governamentais.

\section{Previsão normativa do Ensino Superior}

A educação superior brasileira está lastreada em termos jurídicos por dispositivos constitucionais regulamentados por leis ordinárias que regem o sistema de ensino, em termos nacionais, além de acordos internacionais, tais como a Declaração Mundial sobre Educação Superior no Século XXI. Neste âmbito, o artigo 205 (BRASIL, 1988) prescreve a educação como direito universal, dever do Estado e da família, promovida e incentivada com a colaboração social, para o pleno desenvolvimento da pessoa, do cidadão e do trabalhador. Portanto, os ditames constitucionais determinam que a educação instrumentalize não só a formação humana e suas potencialidades, mas, também capacite o cidadão-trabalhador, estando tal capacitação estritamente relacionada, por óbvio, com o nível superior. 
Entretanto, Zoccoli (2009), a respeito da configuração da educação quando da promulgação da $\mathrm{CF} / 88$, considera que embora haja sido proposta a educação para todos os recursos e os investimentos foram insuficientes para se atingir o pleno desenvolvimento humano previsto. Assim, embora a proposta educacional tenha diretrizes e princípios constitucionais que destacam a garantia de oferta e da qualidade do ensino - tais como, art. 206, VII e art. 209, II -, a educação brasileira, inclusive a superior, tem sido tomada por períodos de grande incerteza.

Tal incerteza se agrava ainda mais quando as políticas educacionais, que demandam um longo período de implantação para efetivamente gerar resultados, passam a ser orientadas por políticas partidárias e perdem o potencial de amplitude de políticas governamentais de Estado, propriamente ditas. Vale ilustrar com um exemplo de Souza (2014) que, referindo-se ao Plano Nacional de Educação de 2001, comenta que o mesmo, previsto pela lei $\mathrm{n}^{\circ}$ 10.172/01, apresentou franca tendência conservadora coerente com os interesses do então governo federal e as medidas econômicas impostas. Especialmente a partir dos planos de expansão educacional o que se tem verificado na pauta da educação brasileira é um esvaziamento da discussão a respeito da própria concepção de 'educação de qualidade'. Entretanto, basta retomar os termos constitucionais acima citados para verificar que os valores que representariam qualidade educacional seriam aqueles que oportunizassem o pleno desenvolvimento humano, o exercício da cidadania e a qualificação para o trabalho (BRASIL, 1988, art. 205).

Para além dos ditames constitucionais, a principal lei que rege a educação no Brasil (1996), inclusive a de nível superior, é a Lei de Diretrizes e Bases (Lei no 9.394/96) que, conforme Zoccoli (2009, p. 110) instaurou “[...] novos parâmetros para a educação no País [sic], devendo os profissionais da educação, em suas ações vincularem-se ao mundo do trabalho e à prática social”, e estabelece níveis de escolaridade que retratam a proposta de educação ao longo da vida.

Vê-se que, a partir do destacado, este estudo tem por foco de síntese os programas de graduação com níveis de ensino "[...] abertos a candidatos que tenham concluído o ensino médio ou equivalente e tenham sido classificados em processo seletivo" (ZOCCOLI, 2009, p. 127), tal caracterização, embora correta, passa por desconfiguração dada a quase inexistência de processos seletivos, no sentido estrito, para o ingresso em instituições de ensino superior privadas, de cunho popular e mercantilista. De qualquer modo, seja de oferta pública ou privada, popular ou elitista, a finalidade da educação superior está estabelecida nos termos dos parágrafos do artigo 43 da LDB/96, possibilitando o delineamento de diversas configurações 
de educação superior, o que converge com o instituído pelo artigo constitucional 206, legitimando variados modelos educacionais, desde que atendidos os padrões mínimos de qualidade pautados pelo Sistema Nacional de Avaliação da Educação Superior (Sinaes).

Entretanto, Morosini et al. (2016) contrapõem que, embora a LDB/96 informe que a educação deva garantir o padrão de qualidade, há indefinição dessa norma quanto ao que seria tal 'padrão de qualidade', caracterizado apenas por seus compromissos. Portanto, é importante considerar que os parâmetros de avaliação da qualidade devem evidentemente estabelecer uma relação direta com a proposta de finalidades dos cursos de graduação sob pena de esfacelamento das diretrizes para além de uma ideia de flexibilização, que devem ser convergentes com os preceitos constitucionais. Ademais das finalidades, outras duas características da educação superior brasileira também devem ser evidenciadas nessa pesquisa, e estão previstas nos artigos 45 e 46, da LDB/96, respectivamente. São elas: a possibilidade de oferta de cursos de graduação por instituições públicas e instituições privadas e o uso de avaliações como mecanismo legitimador de autorizações, reconhecimentos, credenciamentos e classificação das instituições de nível superior.

Nesses termos, a Lei 10.861/04 (BRASIL, 2004), que instituiu o Sinaes, acaba por regulamentar a ideia de avaliação como instrumento de gestão do ensino superior sendo, junto à Portaria MEC 40/2007 (BRASIL, 2007), um dos mais importantes instrumentos norteadores da oferta e qualidade desta modalidade educacional, complementada pela Diretoria de Avaliação da Educação Superior (DAES), responsável pelas avaliações dos cursos e Instituições de Educação Superior, pelo Exame Nacional de Desempenho dos Estudantes (ENADE) e pelos indicadores da educação superior decorrentes de exames oficiais (INEP, 2017).

Passados mais de dez anos da importante Portaria em comento há a institucionalização da Secretaria de Regulação e Supervisão da Educação Superior (Seres), ou seja, um secretariado que se propõe a fazer uma gestão mais fina e acurada do processo de regulação, supervisão, expansão e gestão da qualidade do ensino superior brasileiro, bem como, de zelar pelo cumprimento normativo, sendo talvez uma ação em resposta às denúncias de fraudes aos processos de avaliação das instituições que foram denunciados ao longo dos anos, desde a implantação do Sinaes.

Por outro lado, como inicialmente mencionado, em termos internacionais a Declaração Mundial sobre Educação Superior no Século XXI ressignifica a graduação conferindo-lhe novas missões e reforçando a ideia de educação ao longo da vida, condizente com as 
finalidades propostas pela LDB brasileira, embora estreitamente associada com a ideia utilitarista de educação, como motor para o desenvolvimento econômico.

\section{Aspectos históricos e contextuais}

Segundo Marques (2014, p. 756)

A educação é parte da sociedade; qualquer que ela seja, tenha sido ou venha a ser. Para entendê-la é imprescindível mergulhar em sua história e nas especificidades que a tornaram o que é no presente. Mas para entender o seu sentido mais profundo, é preciso buscar este todo maior de que faz parte, a sociedade que a perpassa.

A partir das razões expostas pelo autor torna-se imprescindível a ilustração de tais aspectos especialmente porque no caso brasileiro o 'ensino superior' traz, em si, características que comportam peculiaridades, entre elas: seu surgimento tardio; a dicotomia do sistema, desde sua gênese; e, por fim, a mudança do perfil do aluno ingressante no ensino superior na contemporaneidade, dadas as políticas públicas que promovem acessibilidade social, bem como, os avanços tecnológicos próprios da sociedade do conhecimento e da informação.

\section{1 "A Universidade Temporã"}

Cunha (1986) - numa trilogia a respeito da história da universidade no Brasil - destaca o atraso, e possíveis razões, do surgimento tardio do ensino superior brasileiro mesmo se comparado à América Latina, bem como, suas características ideológicas de aparelho educacional de exploração da colônia para manter o modelo social, econômico e político (CUNHA, 1986; ZOCCOLI, 2009). Em resumo, a educação superior brasileira criada apenas em 1808 (SAMPAIO, 2000; DURHAM, 2003; ZOCCOLI, 2009; SCHWARTZMAN, 2014), ao tempo da chegada da Coroa Portuguesa, controlada pelo governo central, nesse momento pública, porém não gratuita, tendo a Europa como símbolo e a necessidade de pertencer a uma civilização como bases ideológicas, alimenta a manutenção do status quo dominante, não sendo berço das ideias emancipadoras.

Por outro lado, a educação superior privada no Brasil iniciou-se desde o período republicano, com o advento da Constituição de 1891 (CUNHA, 1986; SAMPAIO, 2000), o que gera, portanto, descentralização e possibilidade de iniciativas dos governos estaduais e setor privado, que potencializou a expansão dessa modalidade de ensino (SAMPAIO, 2000). Segundo Cunha (1986), esse fenômeno foi produzido por determinações técnico-econômicas 
para aumentar a força de trabalho com alta escolaridade, bem como, atender às influências do positivismo.

Percebe-se, portanto, distorcida a visão de que estas instituições privadas, ou a expansão do ensino superior sejam modelos contemporâneos, pois, na verdade correspondem a configurações centenárias do sistema. Quanto à história do setor privado no Brasil, exemplifica Sampaio (2000), que entre 1933-1965 deu-se a consolidação e estabilização desse setor e, em seguida, entre 1965-1980, seu crescimento e predominância, tais circunstâncias foram fomentadas pelo regime militar e sua política restritiva ao ensino público, considerado subversivo. Outro claro exemplo da expansão no período entre 1960-1980 é o crescimento total de matrículas no ensino superior em $480,3 \%$, enquanto no setor privado representaram 843,7\% (SAMPAIO, 2000, p. 53), embora haja, posteriormente (entre 1980-1990) estagnação da demanda e regulamentação constitucional do ensino superior privado com isenção fiscal para os empresários do setor (ZOCCOLI, 2009, p. 84). Ainda mais recentemente, Aguiar (2016, p. 113) destaca, houve uma 'segunda grande expansão' ocorrida “[...] a partir de 1995, no governo de Fernando Henrique Cardoso (1995-2003) e esta prosseguiu, a taxas um pouco decrescentes, durante o governo de Luiz Inácio Lula da Silva (2004-2010)”.

Em que pese tal crescimento, o país ainda mantém pouca tradição em educação superior como se pode observar e o panorama descrito tem acarretado estratégias e políticas públicas de estímulo à melhoria e à oportunização de qualificação da mão de obra que, conforme Sguissardi (2015) visam a expansão quantitativa, não importando se essa se dá como usufruto de um direito público ou como compra de um serviço, produto comercial ou mercadoria. Nesse sentido, Rhoades e Slaughter (2010) discutem a constituição do 'capitalismo acadêmico' que tem permeado todo ensino superior a partir do desenvolvimento, promoção e venda de produtos e inovações que atendam às necessidades da 'indústria mercado' que distorcem a função social da educação superior. E, embora esses autores se refiram ao contexto norte-americano, alguns pontos convergem com a educação superior brasileira. Entre eles destaca-se a combinação entre economia neoliberal e o axioma da eficiência nos processos educacionais, bem como, o fomento às instituições privadas e sua acirrada competitividade em detrimento do sistema público, além dos processos certificadores das avaliações externas. Entretanto, Sampaio (2014, p. 140) pondera:

Fenômeno geral, mas com ritmos diferentes de ocorrência, a expansão do ensino superior tem cores locais: cada sistema nacional responde ao crescimento contínuo da demanda do ensino superior a seu modo, conforme suas trajetórias específicas e relações que historicamente estabeleceu com o Estado e o mercado. 
Entrementes a educação superior brasileira atualmente se estrutura em estreita relação com a globalização, donde se pode observar combinações complexas como a oferta privada de educação superior mercantilista por grupos de empresas internacionais, além disso, " [...] na era da informação, sociedades que transitam em direção a uma economia cada vez mais baseada na intensa exploração do conhecimento avançado (não só do trabalho humano), fragmentação das comunidades e individualização dos sujeitos [...]" (FERNÁNDEZ, 2009, p. 2). Logo, as políticas públicas que fomentam a expansão e o acesso ao ensino superior buscam responder a tais demandas, o que pode gerar distorções importantes em caso de importação pura e simples de modelos e padrões, sem se considerar "as cores locais" (SAMPAIO, 2014) e "as particularidades do sistema já implantado", como ressalta Aguiar (2016). Vale salientar que embora notória a expansão do sistema, ainda está adstrita às regiões mais desenvolvidas do país, atendendo a uma pequena parcela da população, mantendo-se, de certa forma, elitista (ZOCCOLI, 2009).

\subsection{Sistema Dicotômico de Ensino}

Como visto, embora 'temporã' quanto à sua criação e oferta, a educação superior no Brasil apresenta desde sua origem um forte entrelaçamento com o setor privado, destacado por Durham (2003) como um precoce e poderoso sistema paralelo ao sistema público, sendo, tal dicotomia, tema recorrente nas discussões relativas às políticas de Governo que permitiram a instalação do ensino superior privado, desde a primeira República, e sua manutenção, como mote da ampliação de vagas, gerando posições divergentes. Assim, Ristoff (1999) se insurge contra a privatização advertindo que ao invés de atentar para as causas do fracasso deste tipo de opção política e pesar os danos acadêmicos e sociais dela decorrentes, o Brasil insiste em levar o projeto de privatização às suas últimas consequências. E Sguissardi (2015), no mesmo sentido, aponta a distorção entre massificação mercantil e democratização do acesso, que geraria um modelo impeditivo à efetiva democratização do 'subsistema'. Revelando, em ambos os posicionamentos, uma percepção quanto à "[ [...] substituição da universidade como instituição educativa, participante da construção da cidadania e consciência crítica nacional, por um papel que se reduz à formação de profissionais que respondem adequadamente às demandas do mercado" (CUNHA et al., 2005, p. 19).

Outros autores (SAMPAIO, 2000; HALLAK; POISSON, 2007; BRUNNER, 2014; SCHWARTZMAN, 2014), em contrapartida, defendem a ideia de complementariedade dos sistemas e consideram que as instituições públicas têm por limitadores: a pequena oferta de 
vagas, os processos seletivos mais rigorosos e as carreiras voltadas para a elite. A esse respeito Schwartzman (2014) ainda associa razões que elevam o custo do ensino universitário público brasileiro fomentando ainda mais uma estrutura lenta e burocrática que naturalmente vocacionaria a oferta de ensino superior privado à popularização. Ou seja, essa lentidão das instituições públicas relacionada às características de sua estrutura burocrática as tornaria incompatíveis com a necessária agilidade de resposta aos interesses e demandas sociais ainda que às universidades seja dada autonomia de gestão - e, em sentido oposto, Sampaio (2000), num acurado estudo sobre o ensino superior privado, destaca a permeabilidade desse modelo às transformações e demandas sociais, com renovação de propostas de cursos oferecidos, flexibilização curricular e reação mais dinâmica às necessidades do mercado e da sociedade contemporânea.

Hallak e Poisson (2007), numa outra linha argumentativa, consideram que haverá ainda mais demanda para a educação - inclusive superior - o que geraria conflito caso a oferta estivesse adstrita ao sistema público, apontando para o caráter de imprescindibilidade do sistema privado, o que corrobora o argumento anterior quanto a complementaridade dos sistemas. Nesse sentido, se considerado imprescindível e complementar, dada a crescente demanda, também inconteste a necessidade de maior refinamento da fiscalização e controle públicos das instituições privadas, cumprindo, portanto, o Estado seu dever constitucional de zelar pela oferta e qualidade educacionais. Pois, a presença de instituições privadas no Brasil representa $66,33 \%$ da oferta de matrículas para o ensino superior, com destaque para o fato de que $80,9 \%$ dos cursos de curta duração, denominados tecnológicos, estarem concentrados nas instituições particulares, segundo dados de 2014 publicados pelo Inep (2017).

Apesar dessas alegações que defendem a expansão do ensino superior privado, seja pela complementariedade entre os sistemas seja pela necessidade social visando a popularização do ensino superior, permanecem fortes críticas à essa modalidade de ensino, conforme Ristoff (1999) e Sguissardi (2015). Vale ressaltar, entretanto, que os autores em comento não apresentam dados a respeito da comparação quanto à qualidade de ensino da educação superior - pública ou privada - considerando, apenas, que os resultados práticos aduzidos por eles sejam cena validada, portanto, incontestes. Além disso, não são problematizadas as condições de infraestrutura e o notório sucateamento das instituições de ensino superior público, uma vez que a ressaltada qualidade acaba restrita aos poucos grandes centros de excelência universitária. Portanto, em que pese pareça haver uma tendência a se relacionar as instituições públicas à predominância da qualidade de ensino em se comparando 
com as instituições privadas, tal conclusão seria forçosa e precipitada dada a diversidade de instituições públicas e privadas no Brasil.

Além disso, como alerta Sampaio (2000) não se deve generalizar quaisquer estratégias adotadas pelo setor privado, considerando a variedade de tipos e propostas pedagógicas existentes. Nesse sentido, a mesma autora esclarece que as propostas educacionais de iniciativa particular devem ser entendidas a partir de dois modelos distintos: a privatização e a mercantilização do ensino superior. Na primeira afigura-se oferta de proposta educacional de iniciativa privada, pensada por educadores, tais como as universidades comunitárias, enquanto a segunda se orienta pela lógica do lucro mediante a prestação de serviço educacional. Esse cenário de estrutura empresarial ganhou maior amplitude a partir do decreto $n^{\circ}$ 2.306/97 que possibilitou que as mantenedoras do ensino superior adotem natureza civil ou comercial, criando, portanto, maior variabilidade institucional. Nesses termos, à educação superior privada é permitido que estruture relações de consumo, prestação de serviços, captação de clientes, além das negociações de fusões e aquisições e na Bolsa de Valores (SAMPAIO, 2014; SGUISSARDI, 2015), legitimando e favorecendo a oferta de ensino superior mercantilista (SGUISSARDI, 2015) o que gera contrassenso uma vez que a educação é bem público.

Para Sguissardi (2015) esse processo de transformação do direito público em serviço/mercadoria comercial ocorre dentro de um Estado reformado, reestruturado para se ajustar à uma economia ultraliberal, ou seja, um Estado que não representa os interesses públicos, mas tende a priorizar os interesses privado-mercantis. Assim, as instituições privadas, pautadas numa base empresarial-educacional, veem na possibilidade de acesso ao financiamento público uma oportunidade de negócios, fomentando, ou não, a melhoria do ensino, pressionados a apresentarem resultados, tanto institucionais quanto discentes, nas avaliações nacionais. Cunha et al. (2005) destacam que a privatização do ensino superior trouxe um impacto importante para a função docente, qualquer que seja sua orientação institucional - educacional ou mercantilista. Uma vez que ao ofício foi incorporada a lógica empresarial, com a intensificação do trabalho do professor e submissão aos processos de avaliação externa, que mudam qualitativamente o currículo e as práticas institucionais e interferem na sua condição profisssional.

É importante acrescentar que, embora haja o amplo discurso da democratização do ensino superior pelas políticas de acesso, a massificação pela mercantilização do 'produto educação' com empresas privadas dispondo de verbas públicas precisa ser melhor e mais profundamente discutida por educadores e economistas vez que é pública e notória a 
corrupção do sistema político brasileiro como um todo. Nesses termos, segundo Cunha et al. (2005) o Estado substitui os mecanismos tradicionais de regulação por mecanismos de mercado, tais como, o processo de competição com a publicização de resultados das avaliações, gerando ranqueamentos institucionais, o que fomenta a disputa por alunos e recursos públicos, dentro da ótica da eficiência e do lucro. Resultando, conforme adverte Fernández (2009), em mudança do ‘jogo universitário’ submetido às preferências, demandas e oportunidades que o mercado cria e as normas governamentais regulam. De qualquer modo, como bem observa Segrera (2012), independente de sua natureza pública ou privada, o ensino superior tem uma responsabilidade pública fundamental relacionada aos conteúdos curriculares, à ética e aos valores transmitidos; sendo necessário buscar equilíbrio entre o conhecimento economicamente pertinente e o sentido humano, ainda que a formação universitária deva contemplar a esfera profissional.

\subsection{Modificação do Perfil Discente}

A terceira característica do ensino superior elencada diz respeito ao perfil do estudante ingressante que mudou drasticamente, sendo tal transformação resultado de um conjunto de fatores, tais como: ampliação do acesso para camadas sociais mais carentes; alunos egressos do ensino médio com menor domínio das habilidades básicas; surgimento de novas carreiras com forte apelo prático; fomento de instituições para prestação de serviços educacionais com ethos mercantilista; inserção dos "nativos digitais" no ensino superior e avanço de tecnologias portáteis em rede. Os primeiros fatores apontados se inter-relacionam. Assim, nesse sentido, os estudantes brasileiros chegam ao nível superior por meio das propostas de "democratização do ensino", tais estratégias surgem a partir dos programas governamentais do Programa de Apoio aos Planos de Reestruturação e Expansão das Universidades Federais (Reuni), o Programa Universidade para Todos (ProUni), a Universidade Aberta do Brasil (UAB) e o Fundo de Financiamento Estudantil (Fies) além do sistema de cotas, que oportunizam o acesso a instituições públicas e privadas e "[...] o objetivo de ampliar o acesso e a equidade no ensino superior" (SAMPAIO, 2014, p. 174).

Entretanto, Sguissardi (2015) contraria tal suposição e argumenta que tais medidas representam apenas 'políticas focais de curto alcance', que, segundo o mesmo autor, “[...] destinam-se a parcelas da população trabalhadora ou excluída e têm alcance limitado, pois não atuam sobre as causas da desigualdade social produtora da exclusão" (SGUISSARDI, 2015, p. 877). E, nesse sentido, possibilitam condições de acesso, mas não de permanência 
escolar ou de sucesso no mercado de trabalho, o que remete às tendências do liberalismo 'reformista social' (DARDOT; LAVAL, 2016). Servindo aqui o alerta de Esteban (2008, p. 6):

[...] garantir o ingresso e a permanência na escola é condição necessária, mas não suficiente, para produzir uma efetiva democratização do acesso aos conhecimentos socialmente relevantes. Há um aumento expressivo de sujeitos que assumem a condição de aluno, sem, no entanto, uma equivalência na realização das aprendizagens necessárias e/ou validadas, visto que a experiência escolar de muitos é marcada por desempenhos insuficientes e por abandono precoce.

No contexto traçado, as instituições de ensino superior, notadamente as privadas, passam a receber predominantemente os alunos advindos das escolas públicas, cujo nível de preparo é considerado inferior ao dos alunos das escolas particulares, com importantes deficiências educacionais quanto ao domínio esperado dos conteúdos das disciplinas do seu grau de formação. Assim, numa perspectiva de mercado, a qualidade da mão-de-obra ofertada pelos concluintes do ensino médio, demonstra o baixo preparo escolar - configurando, muitas vezes, analfabetismo funcional - que prejudica diretamente seu potencial de empregabilidade, assim, tais indivíduos passam a demandar maior capacitação. E, uma vez egressos do ensino médio, sem retorno possível, e aptos ao ensino superior pretendido a ele ingressam, com todo o cabedal de dificuldades. Esse panorama desenha a manutenção da estrutura social empregados-empregadores - com diferenciação salarial, especialmente se mantida a dicotomia entre o ensino superior das elites - que forma empresários e decisores - e ensino superior das massas - que forma a mão-de-obra e consumidores. Embora, para o economista francês Thomas Piketty (2014) tal processo de expansão e difusão de conhecimentos e competências seria instrumento para o aumento da produtividade e diminuição da desigualdade nacional e internacional, ou seja, a difusão do ensino superior traria potencial melhoria à distribuição de renda na sociedade brasileira.

Entretanto, Dardot e Laval (2016) ponderam que a própria constituição de uma política educacional que visa beneficiar exclusivamente as massas, adaptando a mão-de-obra a uma concorrência generalizada, se configuraria muito mais como instrumento para atender às necessidades da economia de mercado neoliberal do que como política de cunho social propriamente dita, embora haja impactos sociais inegáveis. Nessa educação superior de massa, dadas as condições já comentadas, convergem, portanto, todos os problemas educacionais de base, notadamente nas IES privadas, e assim, sujeitos com perfil de analfabetismo funcional podem chegar aos bancos escolares da educação superior, onde devem discutir demandas da sociedade complexa, sendo ao final avaliados por exames de 
competências e habilidades que visam julgar a formação dada pela instituição e não o nível de preparo do aluno. Takahashi (2015, p. 6) comenta, nesse contexto, que as universidades particulares reclamam gastar tempo e recursos para dar reforço a estudantes não devidamente formados no ensino médio. Cabe ressaltar que esse papel de 'alinhamento' do aluno, a partir de suas dificuldades e má formação na educação básica, distorce e sobrecarrega o ensino superior que, por fim, não cumpre em totalidade sua função. Gerando, desse modo, mudanças qualitativas neste nível de ensino que passaria a assumir "papéis de instrumentação técnica, competência individual e instrumentalização econômica" (DIAS SOBRINHO, 2012, p. 603) que não se inscrevem em suas funções de origem.

Para validar essas ações e com o discurso de qualidade na educação o governo brasileiro adotou na LDB/96 a ideia de certificação educacional em larga escala nos mais diversos níveis, de forma padronizada, cíclica e sistêmica. Esse formato avaliativo que, aplicado ao nível superior denomina-se ENADE (Exame Nacional de Desempenho dos Estudantes) é regulado pela Lei $\mathrm{n}^{\circ} 10.861 / 04$, que junto à avaliação in loco e à avaliação institucional (realizada por meio da Comissão Própria de Avaliação - CPA) forma a tríade que compõe o processo avaliativo-fiscalizatório governamental em busca da aludida qualidade de ensino.

Por outro lado, há que se considerar que alguns setores - de comércio e serviços cujas atividades laborais não guardavam relação com a educação superior passam a ser, por esse nível de ensino, certificadas, e, nesse ponto, chega-se ao terceiro fator comentado ao início deste artigo, qual seja, o surgimento de novas carreiras com forte apelo prático. Conforme Sampaio (2014, p. 153) essas carreiras são aquelas criadas na área de serviços e originadas de profissões de ofício "[...] para as quais ainda não havia - tampouco se exigia formação acadêmica". A respeito do tema o Conselho Nacional de Educação justifica a necessidade de estruturação de tais cursos em parecer (BRASIL, 2001, p. 1), nos seguintes termos: "A educação para o trabalho não tem sido convenientemente tratada pela sociedade brasileira que, em sua tradição, não lhe vem conferindo caráter universal, colocando-a fora da ótica do direito à educação e ao trabalho". Entretanto, essa justificativa ignora a existência de ordenamentos que regulam os cursos técnicos de nível médio no Brasil, como por exemplo, os pareceres CNE/CEB n02/97 (BRASIL, 1997a) (Dispõe sobre os programas especiais de formação pedagógica de docentes para disciplinas do currículo do ensino fundamental, médio e da educação profissional em nível médio), CNE/CEB n¹7/97 (BRASIL, 1997b) (Estabelece diretrizes operacionais para a educação profissional em nível nacional), e a CNE/CEB nº16/99 (BRASIL, 1999) (Diretrizes Curriculares Nacionais para a Educação Profissional de Nível 
Técnico). Ademais, em termos jurídicos, os cursos tecnológicos passam a ser regulamentados pelo decreto $\mathrm{n}^{\circ} 5.154 / 04$, que em seu artigo $5^{\circ}$ dispõe que os cursos de educação profissional tecnológica - de graduação ou pós-graduação - organizarão seus objetivos, características e duração, de acordo com as diretrizes curriculares nacionais, que, posteriormente, foi subsidiariamente aplicado aos cursos técnicos conforme Parecer CNE/CEB n³39/2004 (Aplicação do Decreto n ${ }^{\circ}$ 5.154/04 na Educação Profissional Técnica de nível médio e no ensino médio).

O surgimento de tais cursos tecnológicos denota, portanto, o ápice do processo de atendimento à demanda de educação para o mercado de trabalho. Aproximando-se ao modelo norte-americano de programas a curto prazo comentados por Rhoades e Slaughter (2010) que não são desenhados para melhorar sistematicamente o aprendizado dos estudantes, ou a atender interesses da sociedade, mas capacitá-los às demandas pontuais do mercado. Sampaio (2014) ainda destaca que, uma vez convertidas ao nível superior, essas profissões geram novos mercados educacionais que vêm a suprir os períodos de estagnação da demanda por cursos tradicionais do ensino superior. Com tais características de origem; voltados à educação para o trabalho, oriundos de ofícios relacionados ao comércio e serviços e possibilitando um diploma de curso superior em curto espaço de tempo; tais carreiras acabam por despertar interesse de um público que normalmente não frequentaria a educação superior nas modalidades tradicionais. Em sua grade curricular são compostos por disciplinas com forte apelo prático e, portanto, tais cursos tecnológicos se distanciam da proposta do ensino superior de caráter formativo-crítico, focando principalmente nas tendências de mercado. Por essa razão, vê-se, por parte das IES, a criação e abandono de propostas de cursos, tão logo a demanda reprimida seja atendida. Nesses termos, o Catálogo Nacional de Cursos Superiores na área de tecnologia (BRASIL, 2016), em sua terceira edição, ilustra um total de 134 possibilidades de cursos tecnológicos a serem ofertados, entre eles, a título de exemplo: Curso Superior Tecnológico em Cavalaria, Curso Superior Tecnológico em Rochas Ornamentais e Curso Superior Tecnológico em Processos Escolares.

Por outro lado, o Sindicato das Mantenedoras do Ensino Superior publicou em 2016 o chamado Mapa do Ensino Superior e destaca que no “[...] acumulado de 2009 a 2014, o crescimento [dos cursos tecnológicos] total chegou a 25\%" (SEMESP, 2016, p. 12), com predominante crescimento na rede privada, sendo, pois um negócio economicamente lucrativo.

Assim, com a decrescente qualidade do ensino médio e a expansão do ensino superior privado mercantilista combinado com o advento de cursos superiores em tecnologia torna-se 
previsível o favorecimento do ingresso discente tanto para suprir despreparo cultural quanto propiciar inserção imediata no mercado de trabalho, otimizando seu tempo e recursos. Entretanto, não se pode conjurar uma associação direta entre mercantilismo educacional e cursos tecnológicos, apenas; pois Alonso (2010), ao discutir dados do Inep, destaca que a expansão do ensino superior privado é quantitativa e concentrada em determinadas áreas do conhecimento, com $52 \%$ das matrículas concentradas em cursos como administração, direito e pedagogia. Observa-se, ainda, que no rol listado pela autora há uma interessante relação custo-benefício, uma vez que tais cursos demandam pouco investimento estrutural ou tecnológico por parte das instituições para viabilizar sua oferta. Coerentes, portanto, com o ethos mercantilista.

Nestes termos, cabe ilustrar comparação sugerida por Gruschka (2014) entre a finalidade educacional e a realidade educacional, pautadas pela ideia de 'frieza burguesa' que privilegia o interesse individual sobre o coletivo, perdendo-se, portanto, a noção de função social dos ofícios e profissões que restam adstritas ao sentido de realização pessoal ou financeira. Assim, a finalidade educacional estaria baseada em valores de emancipação - com legitimação dos espaços públicos de educação que ofertariam experiências de ordem moral para o desenvolvimento dos estudantes - enquanto a realidade educacional produziria valores de ordem capitalista estimuladores da padronização e funcionalização dos sistemas, e geradores de competitividade e isolamento, além do desapego às instituições formadoras (GRUSCHKA, 2014). Por outro lado, Cunha et al. (2005) apresentam a hipótese de que há uma profunda modificação da concepção de docência do ensino superior a partir da reconfiguração dada ao sistema educativo pelo contexto político neoliberal que o atinge. $\mathrm{Na}$ concepção neoliberal admite-se a necessidade de uma intervenção do Estado, mas sem se opor ao jogo de concorrências entre interesses privados (DARDOT; LAVAL, 2016).

No que se refere ao último ponto atinente à modificação do perfil discente, tem-se a chegada à graduação das gerações de "nativos digitais" - assim denominados pois têm inseridos, desde muito cedo, em suas vidas o aporte tecnológico, bem como, às tecnologias portáteis em rede - que impelem ao ensino superior mudanças. Essas vão desde a perspectiva didática à estrutural, quanto ao desafio de repensar seu modelo e Projeto Político Pedagógico para atendimento a um público acostumado a pluri-estimulação e incapazes de formulação de pensamento linear, segundo comentam Veen e Vrakking (2009). Nesse sentido, Bender (2014, p. 9) comenta a previsão “[...] de alterações bastante drásticas no processo de ensinoaprendizagem, ocasionadas por tecnologias em constante modificação, pela demanda crescente vinda de estudantes com dificuldades e por várias mudanças que já estão em 
andamento [...]". Ou, como destaca Municio (2003), as novas tendências educacionais mudarão o foco dos saberes, habilidades e atitudes para os componentes cognitivos que apreendem atitudes, valores, hábitos, relações e motivação.

Para Veen e Vrakking (2009) a modificação de abordagens docentes, reposicionando a tecnologia e o acesso ao conhecimento através da rede mundial de computadores, será imprescindível para a manutenção da educação formal, dado o fato das informações estarem inteiramente disponibilizadas, sendo necessário ressignificar o lugar docente que passa a ter um papel de orientador da aprendizagem e, não mais, de detentor dos saberes. Assim, surge ampla discussão a respeito da necessidade de se repensar as práticas educacionais, com propostas pautadas pela aquisição de competências-chave - cognitivas, pessoais e sociais para atuar na era de informação em contextos hiper complexos e buscando alternativas para os denominados wicked problems, conforme orientação do Relatório Delors (2001). Nesse panorama, começam a ser contestadas as concepções de avaliação somativa e certificatória, como o exame em larga escala em análise, uma vez que este se pautaria na ideia de que os sujeitos aprendem em tempos e de formas iguais, o que é considerado uma falácia e, via de consequência, reabrindo a discussão da qualidade da educação como um todo, dados os desafios apontados para o século XXI.

\section{A ideia de qualidade no Ensino Superior}

Aqui, esbarra-se, necessariamente, com a discussão sobre a qualidade de ensino sendo necessário retomar que em termos constitucionais tal fator deve estar associado ao incremente do desenvolvimento humano, exercício da cidadania e qualificação para o trabalho (BRASIL, 1988, art. 205). E Piketty (2014, p. 28) alerta quanto à "disseminação da educação de qualidade", ou seja, "[...] a contribuição do ensino superior às necessidades de 'capital humano' dos respectivos países" (SCHWARTZMAN, 2014, p. 32). Portanto, é preciso criticizar a alegação da 'qualidade' alardeada, e observar se esta está apenas adstrita à legitimação do discurso de 'educação para todos' ou se se pretende, considerando uma possível evolução do sistema educacional e do processo avaliativo, ao longo dos anos, 'formação para todos'.

Ademais a questão da qualidade está diretamente associada à perspectiva das partes interessadas envolvidas no processo educacional. E, nesses termos as instituições de ensino especialmente as privadas - tendem a se ater aos requisitos normativos de qualidade (REAL, 2009), ou seja, ficam adstritas aos padrões mínimos de qualidade, criando uma ideia de 
qualidade legitimada vez que os critérios são formulados pelo Poder Público. No mesmo sentido, Morosini et al. (2016, p. 15) comentam que "[...] o conceito de qualidade sofre o impacto da regulação decorrente das políticas educacionais e da representação da sociedade, com especial destaque ao que se manifesta nos meios de comunicação social”. O que, em termos gerais, cria para a sociedade parâmetros de qualidade pautados na divulgação dos diversos ranqueamentos do sistema, sem que se tenha a devida compreensão do que, de fato, os mesmos significam. Segundo Cária e Oliveira (2015), a partir de 1990, o Estado brasileiro inspirado em modelos internacionais, iniciou uma gestão da qualidade educacional baseada em critérios de eficiência e eficácia. Ou seja, trazem como base ideológica parâmetros semelhantes aos processos de padronização da qualidade do setor produtivo, sugerindo, pois, um modelo educacional afeto aos valores de ordem capitalista. Emergindo deste panorama as formas de regulação dos sistemas de ensino por meio de avaliações em larga escala que, como denotam Cunha et al. $(2005$, p. 25$)$, “[...] adota um padrão de qualidade universal, anulando as especificidades das diferenças, condição básica de uma ação educativa processual”.

Passados mais de vinte anos da introdução dos exames governamentais em larga escala o que se observa põe em xeque não apenas a prática avaliativa como também a própria proposta do sistema educacional, uma vez que não se confirmaram as expectativas de melhoria da qualidade de oferta no ensino superior, mas passaram a ser relatadas estratégias de gestão institucional do exame com o objetivo de melhoria dos resultados dos cursos avaliados $^{1}$. Nesse sentido, os dados que indicam que $48 \%$ dos graduados são analfabetos funcionais (IPM, 2015) reafirmam essa condição gerando questionamentos a respeito da qualidade da educação que vem sendo ofertada no sistema educacional brasileiro como um todo, bem como, dos critérios e modelos da avaliação em larga escala utilizados como padrões de certificação.

\section{Considerações finais}

Pela síntese de dados apresentada pode se observar a constituição de um modelo educacional para o ensino superior brasileiro notadamente privado de caráter mercantilista como estratégia de expansão, em que pese persistirem universidades públicas e privadas educacionais. Por outro lado, essa proposta atende aos interesses do setor privado, embora a

\footnotetext{
${ }^{1}$ Nesse sentido, os dados e notícias são fartamente publicados na mídia brasileira sendo possível, inclusive se observar quando da análise dos dados atinentes ao mídium JFSP.
} 
educação seja direito social e de interesse público, sendo tal desenho compatível com a economia neoliberal, podendo-se, a partir daí, perceber o papel do INEP/MEC como órgão fiscalizador, através das avaliações realizadas.

Pelo já exposto, se pode afirmar, ainda, que a educação de boa qualidade não é produto de geração espontânea, mas um processo que deve conjugar os vários setores envolvidos devendo ser fiscalizado pelo Poder Público a partir de critérios que viabilizem a diminuição das desigualdades socioeconômicas e o fortalecimento multicultural, respeitada a diversidade. Ou seja, o nível de educação da população é diretamente proporcional ao desenvolvimento de um país, portanto, é necessário que se oriente tal educação de forma consistente e estruturada, e se assegure o fortalecimento cultural e o ciclo virtuoso que diminuam diferenças socioeconômicas e ofereçam condições dignas de trabalho e renda. Por outro lado, não parece coerente aferir a qualidade do ensino superior de modo estanque sem considerar a realidade do sistema educacional como um todo. Caso contrário, corre-se o risco de se apontar padrões de educação superior de excelência numa sociedade em que os níveis básicos de educação apresentam resultados modestos.

De qualquer modo, como destaca Brunner (2014), há necessidade de se formular concepções, critérios e instrumentos que assegurem a boa qualidade da educação superior. Para isso, devem ser consideradas todas as suas possibilidades estruturais, pedagógicas e discentes, convergentes com a heterogeneidade presente no sistema, inerente à realidade brasileira, necessária para uma oferta de ensino superior que se pretenda universalizada.

\section{Referências}

AGUIAR, Vilma. Um balanço das políticas do governo Lula para a educação superior: continuidade e ruptura. Revista Sociologia e Política, Curitiba, v. 24, n. 57, p. 113-126, mar. 2016. Acesso em: 15 nov. 2017.

ALONSO, Kátia M. A expansão do ensino superior no Brasil e a EaD: dinâmicas e lugares Revista Educação e Sociedade, Campinas, v. 31, n. 113, p. 1319-1335, out./dez. 2010. Acesso em: 07 set. 2015.

BENDER, William N. Aprendizagem baseada em projetos: educação diferenciada para o século XXI. Porto Alegre: Penso, 2014.

BORGES, Maria Creusa de A. A visão de educação superior do Banco Mundial: recomendações para a formulação de políticas educativas na América Latina. RBPAE, Goiânia, v. 26, n. 2, p. 367-375, maio/ago. 2010. Acesso em: 06 jun. 2018. 
BRASIL. Constituição da República Federativa do Brasil. Brasília: Planalto, 1988.

BRASIL. MINISTÉRIO DA EDUCAÇÃO. Parecer CNE/CEB 02/97. Brasília, 1997a. Disponível em: http://portal.mec.gov.br/setec/arquivos/pdf/RCNE CEB02 97.pdf. Acesso em: 26 jul. 2017.

BRASIL. MINISTÉRIO DA EDUCAÇÃO. Parecer CNE/CEB 17/97. Brasília, 1997b. Disponível em:

http://portal.mec.gov.br/setec/arquivos/pdf_legislacao/rede/legisla_rede_parecer1797.pdf. Acesso em: 26 jul. 2017.

BRASIL. MINISTÉRIO DA EDUCAÇÃO. Parecer CNE/CEB 16/99. Brasília, 1999. Disponível em:

http://portal.mec.gov.br/setec/arquivos/pdf legislacao/rede/legisla rede parecer1699.pdf. Acesso em: 26 jul. 2017.

BRASIL. MINISTÉRIO DA EDUCAÇÃO. Parecer CNE/CES N 436/2001. Brasília, 2001. Disponível em:

http://portal.mec.gov.br/setec/arquivos/pdf_legislacao/rede/legisla_rede_parecer4362001.pdf. Acesso em: 26 jul. 2017.

BRASIL. MINISTÉRIO DA EDUCAÇÃO. Portaria 40/2007: Institui o e-MEC, sistema eletrônico de fluxo de trabalho e gerenciamento de informações relativas aos processos de regulação, avaliação e supervisão da educação superior no sistema federal de educação, e o Cadastro eMEC de Instituições e Cursos Superiores e consolida disposições sobre indicadores de qualidade, banco de avaliadores (Basis) e o Exame Nacional de Desempenho de Estudantes (ENADE) e outras disposições. Brasília: INEP/MEC, 2007. Disponível em: http://download.inep.gov.br/download/condicoes_ensino/2007/Portaria_n40.pdf. Acesso em: 04. jul. 2017

BRASIL. MINISTÉRIO DA EDUCAÇÃO. Catálogo nacional de cursos superiores na área de tecnologia. 3. ed. Brasília: MEC, 2016.

BRASIL. MINISTÉRIO DA EDUCAÇÃO. Presidência da República. Lei 9.394/96: Lei de Diretrizes e Bases da Educação Nacional. Brasília: Congresso Nacional, 1996. Disponível em: http://portal.mec.gov.br/arquivos/pdf/ldb.pdf. Acesso em: 12 ago. 2015.

BRASIL. Lei 10.861/2004: Institui o Sistema Nacional de Avaliação da Educação Superior Sinaes e dá outras providências. Brasília: Congresso Nacional, 2004. Acesso em: 29. Set. 2014.

BRUNNER, José J. La idea de universidad: tendencias y transformación. In: SCHWARTZMAN, Simon. A educação superior na América Latina e os desafios do século XXI. Campinas: Unicamp, 2014. p. 89-105.

CÁRIA, Neide Pena; OLIVEIRA, Sandra Maria. Avaliação em larga escala e a gestão da qualidade da educação. Revista de Ciências Humanas - Educação, Frederico Westphalen, v. 16, n. 26, p. 22-40, jul. 2015. Acesso em: 22 ago. 2016. 
CUNHA, Luiz A. A universidade temporã. 2. ed. Rio de Janeiro: Francisco Alves, 1986.

CUNHA, Maria Isabel da et al. As políticas públicas de avaliação e docência: impactos e repercussões. p. 5-48. In: CUNHA, Maria Isabel da (org.). Formatos avaliativos e concepções de docência. Campinas: Autores Associados, 2005.

DARDOT, Pierre; LAVAL, Christina. A nova razão do mundo: ensaio sobre a sociedade neoliberal. São Paulo: Boitempo, 2016.

DELORS, Jacques. Educação: um tesouro a descobrir. Relatório para a UNESCO da Comissão Internacional sobre Educação para o século XXI. 6. ed. São Paulo: Cortez; Brasília: UNESCO, 2001.

DIAS SOBRINHO, J. Políticas y conceptos de calidad: dilemas y retos. Avaliação, Campinas; Sorocaba, v. 17, n. 3, p. 601-618, nov. 2012. Disponível em: http://www.scielo.br/pdf/aval/v17n3/a03v17n3.pdf. Acesso em: 23 out. 2014.

DURHAM, Eunice R. O ensino superior no Brasil: público e privado. São Paulo: NUPES/USP, 2003.

ESTEBAN, Maria Teresa. Silenciar a polissemia e invisibilizar os sujeitos: indagações ao discurso sobre a qualidade da educação. p. 5-31. Revista Portuguesa de Educação, Universidade do Minho, minho, v. 21, n. 1, 2008.

FERNÁNDEZ, Eduardo. El sistema-mundo del capitalismo académico: procesos de consolidación de la universidad emprendedora. Archivos Analíticos de Políticas Educativas, Arizona State University, v. 17, n. 21, 2009.

GRUSCHKA, Andreas. Frieza burguesa: a frieza como mal-estar moral da cultura burguesa na educação. Campinas: Autores Associados, 2014.

HALLAK, Jacques; POISSON, Muriel. Fraude académico, acreditación y garantía de la calidad: lecciones aprendidas del pasado y retos para el futuro. In: INFORME LA EDUCACIÓN SUPERIOR EN EL MUNDO. Acreditación para garantía de la calidad: ¿Qué está en juego? Madrid: UNESCO, 2007. p. 109-123. Disponível em: http://upcommons.upc.edu/handle/2099/7516. Acesso em: 13 jan. 2017.

INEP. INSTITUTO NACIONAL DE ESTUDOS E PESQUISAS EDUCACIONAIS ANÍSIO TEIXEIRA. Notas estatísticas: censo da educação superior 2016. Brasília: Inep, 2017.

IPM. INSTITUTO PAULO MONTENEGRO. Analfabetismo funcional, opressão de classe e exploração, 15 jul. 2015. Disponível em: http://www.ipm.org.br/ptbr/noticias/saiunaimprensa/Paginas/Analfabetismo-funcional,-opress\%C3\%A3o-de-classe-eexplora\%C3\%A7\%C3\%A3o.aspx. Acesso em: 18. dez. 2016.

MARQUES, Waldemar. Brasil, terra de contrastes. Avaliação, Campinas; Sorocaba, v. 19, n. 3, p. 749-771, nov. 2014. Disponível em: http://www.scielo.br/scielo.php?pid=S141440772014000300011\&script=sci_abstract\&tlng=pt. Acesso em: 26 jul. 2017. 
MOROSINI, Marília C. et al. A qualidade da educação superior e o complexo exercício de propor indicadores. Revista Brasileira de Educação, Rio de Janeiro, v. 21 n. 64, jan./mar. 2016. Acesso em: 12 ago 2017.

MUNICIO, Pedro. Los sistemas de evaluación en la educación superior. Lima: UNE, 2003.

PIKETTY, Thomas. O capital no século XXI. Rio de Janeiro: Intrínseca, 2014.

REAL, Giselle. Avaliação e qualidade no ensino superior: os impactos do período 1995-2002. Revista Educação e Pesquisa, São Paulo, v. 35, n. 3, p. 573-584, set./dez. 2009. Disponível em: http://www.scielo.br/pdf/ep/v35n3/11.pdf. Acesso em: 20/ jul. 2017.

RHOADES, Gary; SLAUGHTER, Sheila. Capitalismo académico en la nueva economía: retos y decisiones. Pasajes: Revista de pensamiento contemporáneo, Valencia, n. 33, p. 4359, 2010. Disponível em: http://roderic.uv.es/handle/10550/45724. Acesso em 23 ago. 2017.

RISTOFF, Dilvo I. Universidade em foco: reflexões sobre a educação superior. Florianópolis: Insular, 1999.

SAMPAIO, Helena Maria S. Ensino superior no Brasil: o setor privado. São Paulo: HUCITEC/FAPESP, 2000.

SAMPAIO, Helena Maria S. Educação superior na América Latina e os desafios do século XXI. In: SCHWARTZMAN, Simon. A educação superior na América Latina e os desafios do século XXI. Campinas: Unicamp, 2014. p. 140-192.

SCHWARTZMAN, Simon. A educação superior e os desafios do século XXI: uma introdução. In: SCHWARTZMAN, Simon. A educação superior na América Latina e os desafios do século XXI. Campinas: Unicamp, 2014. p. 15-45.

SEGRERA, Francisco L. La segunda conferencia mundial de educación superior (UNESCO, 2009) y la visión del concepto de acreditación en las conferencias de UNESCO (1998-2009). Avaliação, Campinas; Sorocaba, v. 17, n. 3, p. 619-636, nov. 2012. Disponível em: http://www.scielo.br/pdf/aval/v17n3/a04v17n3.pdf. Acesso em: $11 \mathrm{dez} .2016$.

SGUISSARDI, Valdemar. Educação superior no Brasil: democratização ou massificação mercantil? Revista Educ. Soc., Campinas, v. 36, n. 133, p. 867-889, out./dez. 2015. Disponível em: www.scielo.br/pdf/es/v36n133/1678-4626-es-36-133-00867.pdf. Acesso em 13 ago. 2017

SEMESP. SINDICATO DAS MANTENEDORAS DO ENSINO SUPERIOR PRIVADO. Mapa do Ensino Superior no Brasil. 2016. Disponível em: http://convergenciacom.net/pdf/mapa_ensino_superior_2016.pdf. Acesso em: 29 jul. 2017.

SOUZA, Donaldo B. de. Avaliações finais sobre o PNE 2001-2010 e preliminares do PNE 2014-2024. Est. Aval. Educ., São Paulo, v. 25, n. 59, p. 40-170, set./dez. 2014. Disponível em: http://www.fcc.org.br/pesquisa/publicacoes/eae/arquivos/1942/1942.pdf. Acesso em: 06 jun. 2018. 
TAKAHASHI, Fábio. Folha de S. Paulo, São Paulo, 5 set. 2015. Especial Gestão Escolar. VEEN, Wim; VRAKKING, Ben. Homo zappiens: educando na era digital. Porto Alegre: Artmed, 2009.

ZOCCOLI, Marilise M. de S. Educação superior brasileira: política e legislação. Curitiba: IBPEX, 2009. 